\title{
3D Image based Customized versus Standard Treatment Planning for Cervical Cancer High Dose Rate Brachytherapy with Tandem and Ovoids
}

Paul Mobit ${ }^{1,2^{\star}}$, Michael C. Baird ${ }^{1}$, Madhava R. Kanakamedala ${ }^{1}$, Waleed F. Mourad ${ }^{1}$, Satyaseelan Packianathan ${ }^{1}$, Srinivasan Vijayakumar $^{1}$ and $^{\text {Claus }}$ Chunli Yang ${ }^{1}$

${ }^{1}$ Department of Radiation Oncology, University of Mississippi Medical Center, 350 West Woodrow Wilson Dr, Jackson, MS 39213, USA

${ }^{2}$ Cameroon Oncology Center, P O Box 1870, Douala, Cameroon

"Corresponding author: Paul Mobit, Associate Professor, Department of Radiation Oncology, University of Mississippi Medical Center, 350 West Woodrow Wilson Dr, Jackson, MS 39213, USA, Tel: 001601815 6930; E-mail: mobit_paul@yahoo.ca

Received date: June 10, 2015, Accepted date: Aug 05, 2015, Publication date: Aug 10, 2015

Copyright: (c) 2015 Mobit P, et al. This is an open-access article distributed under the terms of the Creative Commons Attribution License; which permits unrestricted use; distribution; and reproduction in any medium; provided the original author and source are credited.

\begin{abstract}
Purpose and Objective(s): To investigate the advantages of volumetric treatment planning in HDR brachytherapy for cervical carcinoma compared to standardized loading based on 2-D planning techniques.

Materials and Methods: Our institution uses volume-based 3-D planning for each tandem and ovoid (T\&O) insertion for HDR brachytherapy in the treatment of advanced cervical carcinoma. Here, we attempt to define the benefits of this approach. We re-planned 48 CT-based treatment plans on 12 patients (treated in our facility between February, 2009 and February, 2010) using a commonly used 2-D standard HDR loading of the T\&O. All patients had received 4 fractions of 6.5 Gy or 5 fractions of $5.5 \mathrm{~Gy}$ to point $\mathrm{H}$ or A. The following organs at risk (OARs) were contoured: rectum, bladder, sigmoid, and small bowel. Our customized planning approach required the adjustment of source dwell times and positions to keep doses to the OARs below $80 \%$ of the prescription dose. The standardized HDR planning, however, bases the loading time on the length of the tandem. The dwell time for each tandem source position is the same. The dwell time multipliers for the ovoids were $0.33,0.665$ and 1.0 , proportionate to the $2 \mathrm{~cm}, 4 \mathrm{~cm}$, and $6 \mathrm{~cm}$ tandem length, respectively. The dose to the highest $2 \mathrm{cc}\left(\mathrm{D}_{2 \mathrm{cc}}\right)$ of the OARs were also determined and analyzed.
\end{abstract}

Results: There was a marked change in the value and location of the $D_{2 c c}$ for all OARs from one HDR session to the next in both the standard and customized plans. When the data for the 48 plans were analyzed together, there were no significant differences between the customized plans and the standardized plans. However, when data for the individual plans were analyzed, $35 \%$ of the 2-D based plans did not meet our treatment planning objectives.

Conclusion: Using customized plans for HDR T\&O brachytherapy did not always reduce the doses to the rectum, bladder, sigmoid, and small bowels compared to the standardized plans. The dose to the small bowel could be up to $15 \%$ higher than the dose to point $\mathrm{H}$ or $\mathrm{A}$ in the standard plans indicating that customized plans may be superior to the standardized ones for the treatment of patients where this dose is critical.

Keywords: HDR brachytherapy; Tandem and Ovoids; Organ at risks; Brachytherapy treatment planning

\section{Introduction}

The American Brachytherapy Society (ABS) Task Group Report $[1,2]$ recommends that cervical cancer patients with clinical stage IB2 (lesion confined to the cervix or microscopic lesion greater than T1a/ IA2) to clinical stage IVA (tumor that invades mucosa of bladder or rectum) be treated primarily with concurrent chemo-radiation (external beam) treatment followed by brachytherapy. A survey of oncology programs in the US [3] showed that $85 \%$ of radiation oncology centers have adopted the use of high dose rate (HDR) techniques for the gynecologic (GYN) brachytherapy portions of treatment.

This survey also showed that $43 \%$ of responders were still using film-based planning for their HDR program while 53\% of the responders used a CT dataset for their treatment planning. Among those centers using CT-based planning, only $38 \%$ would contour the bladder, rectum, sigmoid, and small bowels as organs at risk (OAR).

Generally, optimization of the brachytherapy plan is based on the International Commission on Radiation Units and Measurements (ICRU) dose points, dose volume histograms (DVH), or both. Some centers use CT imaging and planning on the first day, and then just use imaging to confirm the applicator placement without re-planning, for subsequent treatment sessions. Some centers use some type of standardized planning even if the applicators are reconstructed from planar x-rays, CT, or MRI datasets.

Given these variations in treatment planning, there exists a significant likelihood of differences in the resulting plans even if the same prescription dose were used. With regard to imaging of the brachytherapy applicator after insertion, 17 centers (24\%) reported that they used plain x-ray films, either alone or in combination with MRI and/or CT. By contrast, CT was the most commonly used imaging modality $(n=41,57 \%) ; 37.5 \%$ of the centers used CT images for every fraction, and $19 \%$ used CT for the first fraction only. A 
Citation: Mobit P, Baird MC, Kanakamedala MR, Mourad WF, Packianathan S, et al. (2015) 3D Image based Customized versus Standard Treatment Planning for Cervical Cancer High Dose Rate Brachytherapy with Tandem and Ovoids. J Nucl Med Radiat Ther 6: 239. doi: $10.4172 / 2155-9619.1000239$

Page 2 of 6

survey by the International Gynecologic Cancer Intergroup (GCIG) also indicated similar results showing that $85 \%$ of respondents used HDR brachytherapy for Stage IB-IIA cervical cancer patients [4] with different brachytherapy fractionation schedules.

Our institution has been using CT-based customized planning for HDR brachytherapy since 2003 and so we have a fairly large data base of cervical cancer patients treated using this technique. We elected to explore the benefit, if any, of customized treatment planning versus standardized loading of the applicator. From our database, we selected patients, who were treated in our facility between February, 2009 and February, 2010. These customized plans had been planned by the same Medical Physicist and Radiation Oncologist team. For each customized CT-based plan generated and used, we created a new plan based on the standardized loading of the tandem and ovoids.

The main objectives of our study were to compare the dose distribution between customized plans that were generated for 12 patients (48 plans) and their corresponding standard plans created using the same CT dataset. We have evaluated the differences in the $\mathrm{D}_{2 \mathrm{cc}}$ for the same patient for different organs at risk for both customized and standard plans. We have also evaluated inter-fraction differences for both standardized plans and customized plans of the day of the implant. An evaluation the composite dose distributions and intra-fraction differences for the same patient was also undertaken.

\section{Materials and Methods}

All cervical cancer patients treated in our department conventionally received external beam radiotherapy comprising 25 fractions of $1.8 \mathrm{~Gy}$ to the whole pelvis followed by 3 to 5 fractions of $1.8 \mathrm{~Gy}$ to the sidewall as a boost. Brachytherapy was initiated after completion of external beam therapy. This is a retrospective study in which we re-planned 48 customized CT-based plans on 12 patients using a commonly used standard HDR loading for T\&O $[5,6]$.

All patients had initially received 4 fractions of 6.5 Gy or 5 fractions of $5.5 \mathrm{~Gy}$ to point $\mathrm{H}$ or $\mathrm{A}$. In order to simplify the analysis we renormalized the dose for each fraction to $7 \mathrm{~Gy}$ for 4 fractions and only considered the first four fractions in the analysis if the patient had received more than 4 fractions. The following organs at risk (OARs) were contoured: rectum, bladder, sigmoid and small bowels. The mean age of the patients employed in this study was 51 years (range 29 to 86 years). Distributions of the diseases were as follows: $50 \%$ stage IIIB, $30 \%$ stage IIB, $10 \%$ stage IB; another $10 \%$ were stage IA2.

All patients reported in this study underwent our standard brachytherapy treatment pre-procedures which include a routine bowel preparation procedure in the morning of the procedure day. Patients were also required to be on a clear liquid diet on the day prior to the procedure. Following induction of anesthesia, a Foley catheter was aseptically placed in the bladder; the bladder balloon contained 7 $\mathrm{mL}$ of contrast.

The tandem and ovoids implant was then inserted and positioned by the radiation oncologist. Computerized tomographic simulation usually took place immediately after recovery of the patient from sedation. Two millimetre thick slices were obtained during CT simulation. The CT data set was then transferred to the brachytherapy treatment planning system for planning. This study was approved by our institutional review board.
The Varian Brachyvision ${ }^{\mathrm{TM}}$ Treatment Planning System version 8.9 was used to generate all the plans reviewed and reported in this study. Customized planning involved manually adjusting the dwell times and positions of the radioactive source to meet our institutional criteria. Once an acceptable plan was achieved and approved by the radiation oncologist, $2^{\text {nd }}$ check of the plan was completed, the machine parameters were verified, and the dose was delivered. For the standardized HDR treatment planning, the dose calculation was based on the length of the tandem [6].

The dwell time for each tandem source position was the same. The dwell time multipliers for the ovoids were $0.33,0.665$ and 1.0, proportionate to the $2 \mathrm{~cm}, 4 \mathrm{~cm}$, and $6 \mathrm{~cm}$ tandem length, respectively. Each ovoid had three dwell positions set in the middle of the ovoid. The step size was $2.5 \mathrm{~mm}$ for both the tandem and ovoids. For the 2 $\mathrm{cm}$ long tandem, the dwell positions were 1 and 4 ; for the $4 \mathrm{~cm}$ long tandem, the source dwell positions were $1,4,6,8$, and 11 ; and for the 6 $\mathrm{cm}$ long tandem, the dwell positions were 1, 3, 5, 8, 11, 14, 17 and 20.

Thus, for each CT dataset for which a customized plan was generated and used to treat a patient, we then generated a standard plan based with the dwell positions above and renormalized it to give the prescription dose at either point $\mathrm{A}$ or $\mathrm{H}$, depending on how the prescription was initially delivered. For the customized plans, the tandem was fully loaded with source separation of $0.5 \mathrm{~cm}$ and the ovoids would have 3-4 source positions. Our customized planning required the adjustment of source dwell times to keep $D_{2 c c}$ to OARs below $80 \%$ of the prescription dose. A paired student T-test was used to determine the significance in difference between the customized planning and standardized planning/loading.

\section{Results and Discussions}

Table 1 shows the $D_{2 c c}$ for the bladder, rectum, sigmoid, and small bowel for all the patients and for all the fractions. In Table 1, the first four rows belong to patient number 1 , the next 4 rows correspond to patient number 2 , and so forth until the $12^{\text {th }}$ patient.

\section{From Table 1, we can observe the following:}

(a) Irrespective of whether a customized plan or a standardized plan was used, there were significant changes from one fraction to the next for the $\mathrm{D}_{2 \mathrm{cc}}$ for all the organs at risk. The change was as much as $50 \%$ or more-increase or decrease of dose. This suggested that we cannot routinely assume that if the dose to an organ at risk is low or high in the first fraction, it would not necessarily remain low or high in the next fraction.

(b) It can also be noted that the greatest changes in the dose to the organs at risk happen to occur within the sigmoid and small bowel which have been traditionally not been contoured as OAR, as reported by the recent ABS survey (3).

(c) The average $D_{2 c c}$ for all organs at risk was about 4 Gy per fraction which represented about $57 \%$ of the prescribed dose; it has been traditionally assumed that the sigmoid colon and small bowel will not receive any significant dose.

(d) Table 1 also shows that there is no significant difference between $D_{2 c c}$ of organs at risk obtained using the customized or standardized planning except possibly for the rectum where the dose is generally smaller but the difference is not statistically significant. This may be a consequence of too few patients in our analysis. 
Citation: Mobit P, Baird MC, Kanakamedala MR, Mourad WF, Packianathan S, et al. (2015) 3D Image based Customized versus Standard Treatment Planning for Cervical Cancer High Dose Rate Brachytherapy with Tandem and Ovoids. J Nucl Med Radiat Ther 6: 239. doi: $10.4172 / 2155-9619.1000239$

Page 3 of 6

\begin{tabular}{|c|c|c|c|c|c|c|c|}
\hline $\begin{array}{l}\text { Bladder } \\
\text { (Customized } \\
\text { Plan) }\end{array}$ & $\begin{array}{l}\text { Bladder } \\
\text { (Standardized } \\
\text { Plan) }\end{array}$ & $\begin{array}{l}\text { Rectum } \\
\text { (Customized plan) }\end{array}$ & $\begin{array}{l}\text { Rectum } \\
\text { (Standardized } \\
\text { Plan) }\end{array}$ & $\begin{array}{l}\text { Sigmoid } \\
\text { (Customized } \\
\text { plan) }\end{array}$ & $\begin{array}{l}\text { Sigmoid } \\
\text { (Standardized } \\
\text { Plan) }\end{array}$ & $\begin{array}{l}\text { Bowels } \\
\text { (Customized plan) }\end{array}$ & $\begin{array}{l}\text { Bowels } \\
\text { (Standardized } \\
\text { plan) }\end{array}$ \\
\hline 4.05 & 4.20 & 4.78 & 4.85 & 3.31 & 4.85 & 3.00 & 2.95 \\
\hline 4.07 & 2.87 & 3.36 & 3.82 & 3.65 & 3.82 & 3.34 & 2.77 \\
\hline 3.51 & 3.64 & 3.79 & 6.04 & 3.88 & 6.04 & 3.7 & 3.84 \\
\hline 3.88 & 3.69 & 4.21 & 4.78 & 4.32 & 4.78 & 2.14 & 2.31 \\
\hline 3.46 & 3.84 & 4.20 & 4.53 & 3.34 & 4.53 & 6.81 & 7.71 \\
\hline 3.60 & 4.97 & 4.82 & 4.38 & 1.52 & 4.38 & 1.76 & 1.83 \\
\hline 3.42 & 3.01 & 4.94 & 4.38 & 5.46 & 4.38 & 2.55 & 2.54 \\
\hline 5.30 & 4.48 & 4.63 & 3.96 & 2.03 & 3.96 & 3.94 & 3.36 \\
\hline 3.67 & 2.99 & 2.29 & 1.47 & 5.34 & 1.47 & 3.58 & 4.06 \\
\hline 2.60 & 2.26 & 1.30 & 1.01 & 4.61 & 1.01 & 4.37 & 4.53 \\
\hline 2.77 & 1.96 & 1.00 & 0.70 & 3.46 & 0.70 & 5.63 & 5.43 \\
\hline 3.01 & 2.03 & 1.50 & 1.06 & 4.47 & 1.06 & 4.5 & 4.67 \\
\hline 4.73 & 5.44 & 5.11 & 4.13 & 5.46 & 4.13 & 6.68 & 4.89 \\
\hline 4.57 & 4.04 & 3.38 & 4.34 & 6.96 & 4.34 & 5.01 & 3.78 \\
\hline 4.69 & 4.22 & 2.51 & 1.93 & 5.69 & 1.93 & 3.91 & 3.15 \\
\hline 3.42 & 3.03 & 3.41 & 4.36 & 5.01 & 4.36 & 5.62 & 5.51 \\
\hline 4.45 & 4.28 & 4.19 & 4.54 & 4.36 & 4.54 & 4.67 & 5.06 \\
\hline 4.77 & 5.32 & 2.72 & 3.65 & 4.48 & 3.65 & 3.82 & 4.00 \\
\hline 4.56 & 4.48 & 4.49 & 4.91 & 3.68 & 4.91 & 5.27 & 5.1 \\
\hline 4.92 & 5.19 & 3.37 & 4.24 & 3.61 & 4.24 & 2.36 & 2.35 \\
\hline 5.08 & 6.00 & 4.97 & 5.17 & 3.46 & 5.17 & 3.76 & 3.64 \\
\hline 5.14 & 5.52 & 3.60 & 4.11 & 4.67 & 4.11 & 3.84 & 3.12 \\
\hline 4.41 & 4.55 & 4.25 & 6.00 & 4.13 & 6.00 & 5.35 & 5.25 \\
\hline 4.64 & 4.55 & 4.90 & 4.93 & 4.21 & 4.93 & 2.59 & 2.68 \\
\hline 4.97 & 4.49 & 4.91 & 3.88 & 4.02 & 3.88 & 4.59 & 4.12 \\
\hline 3.37 & 3.23 & 3.01 & 3.60 & 4.64 & 3.60 & 5.2 & 5.59 \\
\hline 4.94 & 4.14 & 4.07 & 3.91 & 4.69 & 3.91 & 5.51 & 5.64 \\
\hline 5.58 & 6.06 & 3.21 & 3.84 & 2.28 & 3.84 & 5.2 & 5.89 \\
\hline 3.84 & 3.08 & 4.07 & 4.56 & 3.88 & 4.56 & 2.74 & 2.67 \\
\hline 3.72 & 4.17 & 3.66 & 5.61 & 4.17 & 5.61 & 2.27 & 4.27 \\
\hline 3.97 & 5.51 & 3.46 & 4.71 & 4.26 & 4.71 & 5.73 & 6.17 \\
\hline 4.37 & 4.25 & 3.33 & 3.74 & 4.33 & 3.74 & 2.7 & 1.77 \\
\hline 5.49 & 5.52 & 4.47 & 4.74 & 3 & 4.74 & 3 & 3.23 \\
\hline 6.00 & 6.52 & 3.34 & 3.40 & 1.39 & 3.40 & 4.54 & 3.39 \\
\hline
\end{tabular}


Citation: Mobit P, Baird MC, Kanakamedala MR, Mourad WF, Packianathan S, et al. (2015) 3D Image based Customized versus Standard Treatment Planning for Cervical Cancer High Dose Rate Brachytherapy with Tandem and Ovoids. J Nucl Med Radiat Ther 6: 239. doi: $10.4172 / 2155-9619.1000239$

Page 4 of 6

\begin{tabular}{|c|c|c|c|c|c|c|c|}
\hline 5.12 & 5.03 & 4.79 & 4.60 & 2.39 & 4.60 & 4.54 & 3.39 \\
\hline 4.96 & 5.65 & 5.75 & 6.23 & 3.38 & 6.23 & 2.64 & 1.97 \\
\hline 4.95 & 5.11 & 2.69 & 3.14 & 4.34 & 3.14 & 3.6 & 4.42 \\
\hline 5.11 & 4.65 & 2.66 & 2.71 & 4.63 & 2.71 & 5.4 & 6.07 \\
\hline 5.91 & 5.32 & 3.89 & 2.86 & 5.52 & 2.86 & 5.61 & 5.78 \\
\hline 5.66 & 5.39 & 4.90 & 3.34 & 5.15 & 3.34 & 5.61 & 4.93 \\
\hline 3.09 & 2.86 & 3.09 & 3.88 & 2.73 & 3.88 & 4.91 & 5.57 \\
\hline 4.13 & 3.96 & 2.95 & 3.43 & 3.08 & 3.43 & 3.08 & 4.03 \\
\hline 3.64 & 2.99 & 2.77 & 2.71 & 4.52 & 2.71 & 4.52 & 4.58 \\
\hline 3.69 & 3.49 & 2.62 & 3.64 & 3.16 & 3.64 & 3.58 & 3.67 \\
\hline 4.02 & 4.48 & 3.41 & 4.22 & 1.77 & 4.22 & 3.49 & 5.73 \\
\hline 4.17 & 4.09 & 2.70 & 2.97 & 2.46 & 2.97 & 2.81 & 2.68 \\
\hline 4.12 & 4.26 & 2.50 & 2.67 & 3.02 & 2.67 & 1.87 & 1.37 \\
\hline 4.10 & 4.28 & 2.87 & 3.29 & 2.42 & 3.29 & 2.72 & 3.26 \\
\hline \multicolumn{8}{|c|}{ Mean and Statistical Analysis for all the patients } \\
\hline $\begin{array}{l}\text { Bladder } \\
\text { (Custom Plan) }\end{array}$ & $\begin{array}{l}\text { Bladder } \\
\text { (Standardized } \\
\text { Plan) }\end{array}$ & $\begin{array}{l}\text { Rectum } \\
\text { (Customized plan) }\end{array}$ & $\begin{array}{l}\text { Rectum } \\
\text { (Standardized } \\
\text { Plan) }\end{array}$ & $\begin{array}{l}\text { Sigmoid } \\
\text { (Customized } \\
\text { plan) }\end{array}$ & $\begin{array}{l}\text { Sigmoid } \\
\text { (Standardized } \\
\text { Plan) }\end{array}$ & $\begin{array}{l}\text { Bowels } \\
\text { (Customized plan) }\end{array}$ & $\begin{array}{l}\text { Bowels } \\
\text { (Standardized } \\
\text { plan) }\end{array}$ \\
\hline $4.23 \mathrm{~Gy}$ & 4.25 Gy & 3.55 Gy & 3.93 Gy & 3.95 Gy & $4.03 \mathrm{~Gy}$ & $3.98 \mathrm{~Gy}$ & 3.94 Gy \\
\hline \multicolumn{2}{|c|}{$P$ value (student $t$ test) 0.47} & \multicolumn{2}{|c|}{$P$ value (student $t$ test) 0.06} & \multicolumn{2}{|c|}{$P$ value (student $t$ test) 0.36} & \multicolumn{2}{|c|}{$P$ value (student $t$ test) 0.45} \\
\hline
\end{tabular}

Table 1: $\mathrm{D}_{2 \mathrm{cc}}$ for bladder, rectum, sigmoid and small bowels for all fractions and for all patients in the study group.

Even though the data as a whole did not show an advantage for customized or standardized plans, within individual patients, however, the effect of customization was marked. For instance, in 17 out of the 48 fractions (35\%), we did not achieve our planning objective of keeping the $D_{2 c c}$ for each organ at risk below $80 \%$ of the prescription dose. In one case (patient number 2,1 st fraction), the $\mathrm{D}_{2 \mathrm{cc}}$ was actually $\sim 10 \%$ above the prescription dose of $7 \mathrm{~Gy}$. We found a marked difference in the $\mathrm{D}_{2 c c}$ for all OARs from one HDR session to the next; thus, we believe that with both standardized \& customized plans, a new CT simulation and treatment planning with each insertion is clearly justified. One advantage of HDR over low dose rate (LDR) brachytherapy is that dose to organs at risk can be more readily customized. In our clinical cases, when we could not achieve a $D_{2 c c}$ of $80 \%$ or lower to the organs at risk, we would generally increase the number of fractions and decrease the dose per fraction; this is why in our series some patient had more than 4 fractions. Initially, we had only contoured the bladder and rectum as OAR and optimized the dose to these two structures. In subsequent patients, we implemented contouring of sigmoid and small bowel. Thus, in our series, we did not meet the original sigmoid and small bowel objectives in some of the patients even with customized planning as these organs were never taken into account. If the treatment planning were systematically performed only for the first treatment fraction or if we had used standardized planning, we would have been unable to modify the OAR dose or even change the dose per fraction to accommodate critical OAR doses.

Table 2 shows the same data as in Table 1, but this time we have added the doses for all the fractions to determine the total $D_{2 c c}$ received by each organ during their brachytherapy treatments. Again we observed that there were no significant differences between the customized plans and the standardized plans for all the organs. The greatest difference is with the rectum where the difference between customized plans and the standardize plans is $\sim 1.4$ Gy but yet not quite statistically significant. We also noted a significant difference between each individual patient for all the organs at risks. For instance, the $\mathrm{D}_{2 c \mathrm{cc}}$ for patient number 10 for the bladder is less than $50 \%$ of the $\mathrm{D}_{2 \mathrm{cc}}$ for the bladder for patient number 11 with customized planning. Although the individualized plans tended to reduce dose to bladder, rectum and sigmoid, when the data were analyzed for the group as a whole, there were no statistical differences noted.

There are some shortcomings in the determination of the total dose to the patient's organs at risk in this fashion as the structure may move (especially the sigmoid and the small bowel) and the implant orientation and position may not precisely match for each successive implant. Even our contouring of the OAR is subject to inter-fraction variations. Hence, the maximal $D_{2 c c}$ may not occur at the same location every time a treatment is delivered. So the data presented in Table 2 may simply provide an indication of the maximum dose 
Citation: Mobit P, Baird MC, Kanakamedala MR, Mourad WF, Packianathan S, et al. (2015) 3D Image based Customized versus Standard Treatment Planning for Cervical Cancer High Dose Rate Brachytherapy with Tandem and Ovoids. J Nucl Med Radiat Ther 6: 239. doi: $10.4172 / 2155-9619.1000239$

Page 5 of 6

received by the organs at risk, somewhere within their regions that had been contoured. The best option of determining the total dose received by organs at risk may be to merge the CT dataset and doses from each plan to the original CT dataset. Figure 1 shows the composite treatment course on such fused CT images on Patient 10 (Table 2). This was performed by co-registering all subsequent CT data set with the original dataset using the pixel-to-pixel image fusion algorithm available with the Brachyvision Treatment Planning System. In this patient though it clearly showed a marked reduction of the dose to the bladder and rectum when the customized plan was utilized. Not only is the $\mathrm{D}_{2 c \mathrm{cc}}$ lower than that for the standard plans, but we also saw a significant difference in the lower dose ranges of $\mathrm{V}_{35 \%}$ and $\mathrm{V}_{50 \%}$ - the percent volume of the OAR receiving $35 \%$ and $50 \%$ of the prescription dose, respectively. It is important to note that our study design is slightly different from previous studies which have examined the effects of not re-planning after the initial plan is developed [7-9].

\begin{tabular}{|c|c|c|c|c|c|c|c|c|}
\hline \multirow{2}{*}{$\begin{array}{l}\text { Patient } \\
\text { number }\end{array}$} & \multicolumn{8}{|c|}{ Customized plans versus Standardized planning } \\
\hline & $\begin{array}{l}\text { Bladder } \\
\text { (Customized } \\
\text { plan) }\end{array}$ & $\begin{array}{l}\text { Bladder } \\
\text { (Standardized } \\
\text { Plan) }\end{array}$ & $\begin{array}{l}\text { Rectum } \\
\text { (Customized } \\
\text { plan) }\end{array}$ & $\begin{array}{l}\text { Rectum } \\
\text { (Standardized } \\
\text { Plan) }\end{array}$ & $\begin{array}{l}\text { Sigmoid } \\
\text { (Customized } \\
\text { plan) }\end{array}$ & $\begin{array}{l}\text { Sigmoid } \\
\text { (Standardized } \\
\text { Plan) }\end{array}$ & $\begin{array}{l}\text { Bowels } \\
\text { (Customized } \\
\text { plan) }\end{array}$ & $\begin{array}{l}\text { Bowels } \\
\text { (Standardized } \\
\text { plan) }\end{array}$ \\
\hline Patient 1 & 15.5 & 14.4 & 16.1 & 19.49 & 15.2 & 16.63 & 12.2 & 11.87 \\
\hline Patient 2 & 15.8 & 16.3 & 18.6 & 17.3 & 12.4 & 12.9 & 15.1 & 15.4 \\
\hline Patient 3 & 12.1 & 9.2 & 6.1 & 4.2 & 17.9 & 17.3 & 18.1 & 18.7 \\
\hline Patient 4 & 17.4 & 16.7 & 14.4 & 14.8 & 23.1 & 21.9 & 21.2 & 17.3 \\
\hline Patient 5 & 18.7 & 19.3 & 14.8 & 17.3 & 16.1 & 15.9 & 16.1 & 16.5 \\
\hline Patient 6 & 19.3 & 20.6 & 17.7 & 20.2 & 16.5 & 18.0 & 15.5 & 14.7 \\
\hline Patient 7 & 18.9 & 17.9 & 15.2 & 15.2 & 15.6 & 16.3 & 20.5 & 21.2 \\
\hline Patient 8 & 15.9 & 17.0 & 14.5 & 18.6 & 16.6 & 17.4 & 13.4 & 14.9 \\
\hline Patient 9 & 21.6 & 22.7 & 18.4 & 19.0 & 10.2 & 8.8 & 14.7 & 12.0 \\
\hline Patient 10 & 10.0 & 13.2 & 10.2 & 16.7 & 12.0 & 13.2 & 7.9 & 7.7 \\
\hline Patient 11 & 21.6 & 20.5 & 14.1 & 12.1 & 19.6 & 19.1 & 20.2 & 21.2 \\
\hline Patient 12 & 14.6 & 13.3 & 11.4 & 13.7 & 13.5 & 15.1 & 16.1 & 17.9 \\
\hline Average & 16.8 & 16.8 & 14.1 & 15.5 & 15.3 & 15.6 & 15.5 & 15.6 \\
\hline $\begin{array}{lr}P & \text { value } \\
\text { (student } & \mathrm{t} \\
\text { test) } & \end{array}$ & \multicolumn{2}{|l|}{0.49} & \multicolumn{2}{|l|}{0.18} & \multicolumn{2}{|l|}{0.42} & \multicolumn{2}{|l|}{0.49} \\
\hline
\end{tabular}

Table 2: Customized plans versus Standardized planning.

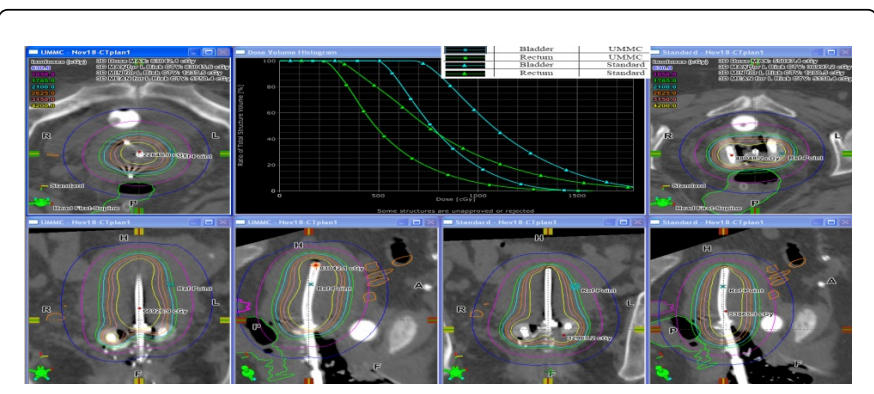

Figure 1: Comparison of the isodoses on the axial, coronal, and sagittal images and the dose volume histogram for the customized and standard plan. The doses from the all 4 treatments delivered to patient \#10 are displayed on the $1^{\text {st }}$ fraction CT dataset.

\section{Conclusion}

Although the use of standardized loading techniques in our 12 patients did not demonstrate statistical inferiority, when individual patients were analyzed, over one-half of the cohort received a dose in excess of $110 \%$ to one or more of the organs at risk for treatmentrelated complications. This could be clinically significant in the long term. The use of MRI based 3-D treatment planning should always be considered, as the CT often was not as sensitive at defining loops of small bowel lying on the uterus versus leiomyomata causing confusion in precisely defining the small bowel extent and its dose. Our results are also consistent with the results of these previous studies which indicate that individual planning is necessary for each insertion of the applicator irrespective of whether a customized planning was initially done. 
Citation: Mobit P, Baird MC, Kanakamedala MR, Mourad WF, Packianathan S, et al. (2015) 3D Image based Customized versus Standard Treatment Planning for Cervical Cancer High Dose Rate Brachytherapy with Tandem and Ovoids. J Nucl Med Radiat Ther 6: 239. doi: $10.4172 / 2155-9619.1000239$

Page 6 of 6

\section{Conflict of Interest}

All authors certify that this manuscript has not been published in whole or in part nor is it being considered for publication elsewhere. The authors indicate no disclosure of potential conflicts of interest.

\section{References}

1. Viswanathan AN, Thomadsen B; American Brachytherapy Society Cervical Cancer Recommendations Committee; American Brachytherapy Society (2012) American Brachytherapy Society consensus guidelines for locally advanced carcinoma of the cervix. Part I: general principles. Brachytherapy 11: 33-46.

2. Viswanathan AN, Beriwal S, De Los Santos JF, Demanes JD, Gaffney D, et al. (2012) American Brachytherapy Society consensus guidelines for locally advanced carcinoma of the cervix. Part II: High-dose-rate Brachytherapy. Brachytherapy 11: 47-52.

3. Viswanathan AN, Erickson BA (2010) Three-dimensional imaging in gynecologic brachytherapy: a survey of the American Brachytherapy Society. Int J Radiat Oncol Biol Phys 76: 104-109.

4. Viswanathan AN, Creutzberg CL, Craighead P, McCormack M, Toita T, et al. (2012) International brachytherapy practice patterns: a survey of the
Gynecologic Cancer Intergroup (GCIG). Int J Radiat Oncol Biol Phys 82: 250-255.

5. Han I, Malviya V, Chuba P, Orton C, Devi S, et al. (1996) Multifractionated high-dose-rate brachytherapy with concomitant daily teletherapy for cervical cancer. Gynecol Oncol 63: 71-77.

6. Jones ND, Rankin J, Gaffney DK (2004) Is simulation necessary for each high-dose-rate tandem and ovoid insertion in carcinoma of the cervix? Brachytherapy 3: 120-124.

7. Chakraborty S, Patel FD, Patil VM, Oinam AS, Sharma SC1 (2014) Magnitude and Implications of Interfraction Variations in Organ Doses during High Dose Rate Brachytherapy of Cervix Cancer: A CT Based Planning Study. ISRN Oncol 2014: 687365.

8. Melanie TM, Davidson I, Yuen J, David P. D'Souza J, Batchelar DL (2008) Image-guided cervix high-dose-rate brachytherapy treatment planning: does custom computed tomography planning for each insertion provide better conformal avoidance of organs at risk?" Brachytherapy 7: 37-42.

9. Kirisits C, Lang S, Dimopoulos J, Oechs K, Georg D, et al. (2006) Uncertainties when using only one MRI-based treatment plan for subsequent high-dose-rate tandem and ring applications in brachytherapy of cervix cancer. Radiother Oncol 81: 269-275. 